\title{
T’構造銅酸化物超伝導体の電子状態に対する還元アニール効果
}

浅野 駿，藤田 全基 ${ }^{*}$

（東北大学大学院理学研究科, 東北大学金属材料研究所）

\section{Reduction Annealing Effects on Electronic States in T'-structured Cuprate Superconductor}

\section{Shun Asano and Masaki Fujita*}

Graduate School of Science and Institute for Materials Research*, Tohoku University

\section{$000000 \bullet \bullet \bullet \bullet ० ० ० ० ० 00000000 \bullet$}

\begin{abstract}
In this article, we introduce recent studies of reduction annealing effects on physical properties in T'-structured cuprate oxide using quantum beam spectroscopy. Our $\mathrm{Cu}$ $K$-edge x-ray absorption near-edge structure (XANES) study on the electronic states of T'-structured $\mathrm{Pr}_{2-x} \mathrm{Ce}_{x} \mathrm{CuO}_{4+\alpha-\delta}$ clearly shows increase of number of electron at the copper sites due to annealing, similar to the case of Ce substitution. The qualitative analyses, furthermore, suggest the emergence of holes as well as electrons in the heavily Ce-doped $\operatorname{Pr}_{2-x} \mathrm{Ce}_{x} \mathrm{CuO}_{4+\alpha-\delta}$ due to annealing. The role of annealing procedure, which is necessary for the appearance of superconductivity in T'-structured cuprates, is discussed in connection with recent photoemission spectroscopy and muon spin relaxation/rotation studies.
\end{abstract}

Keywords: high-T $T_{\mathrm{c}}$ superconductor, $T^{\prime}$-structured cuprates, Reduction annealing effects

\section{1.はじめに}

$\mathrm{CuO}_{2}$ 面を有する層状銅酸化物では，キャリア制 御により長距離反強性磁気秩序が抑制されて高温 超伝導が発現する。キャリアの無い状態は，強い 電子相関により実現した反強磁性モット絶縁体で あり，キャリア数の増加により弱相関金属状態へ 移り変わるという基本描像が出来上がっている. 磁気秩序が消失するドープ量領域でも, 磁気摇ら ぎが強固に存在するため，スピン相関が高温超伝 導の発現に本質的な役割を担っていると考えられ てきた。しかし，最近，この定説に異を唱える研 究結果が示されている.

$\mathrm{CuO}_{4}$ の平面 4 配位構造を有する $\mathrm{Nd}_{2} \mathrm{CuO}_{4}$ ( $\left(\mathrm{T}^{\prime}\right)$ 構造 $R E_{2} \mathrm{CuO}_{4}(R E=\mathrm{Pr}, \mathrm{Nd}, \mathrm{Sm}, \mathrm{Eu})$ は (Fig. 1(a))， 電子ドープ型超伝導体の母物質であり, $\mathrm{K}_{2} \mathrm{NiO}_{4}$ (T)構造を持つホールドープ型超伝導体の母物質 $\mathrm{La}_{2} \mathrm{CuO}_{4}$ と同様，モット絶縁体であると長年考え られてきた。 T構造の特徴は, 試料が合成できる 全電子ドープ量領域で as-grown 試料は超伝導を示 さず，超伝導化には還元熱処理（アニール処理） が必要なことである[1]. As-grown 試料は，Fig. 1 (b)のように高 Ce 置換領域でも反強磁性秩序を示 す絶縁体で，還元アニールを施すと Fig. 1(c)のよ うに磁気秩序が抑制され，磁気秩序相が消失した 高濃度領域では超伝導が出現する。この違いは, as-grown 試料で $\mathrm{Cu} の$ 上下位置に部分的 ( 3\%) に
存在する過剩酸素がアニールにより除去されるこ とに起因すると考えられている.この Fig. 1(c)の 相図が電子ドープによる物性変化の本質として, これまでにもホールドープ系と比較研究が行われ

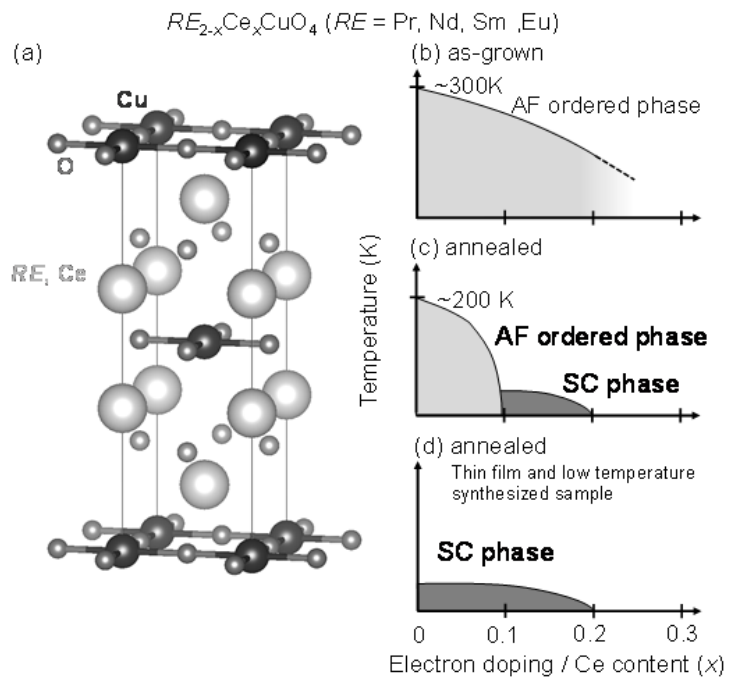

Fig. 1(a) Crystal structure of $\mathrm{T}^{\prime}-R E_{2-x} \mathrm{Ce}_{x} \mathrm{CuO}_{4}(R E=\mathrm{Pr}$, $\mathrm{Nd}, \mathrm{Sm}, \mathrm{Eu})$. Magnetic and superconducting phase diagram for (a) as-grown, (b) annealed, and (c) annealed thin film and low temperature synthesized sample of $\mathrm{T}^{\prime}-R E_{2-x} \mathrm{Ce}_{x} \mathrm{CuO}_{4}$. 

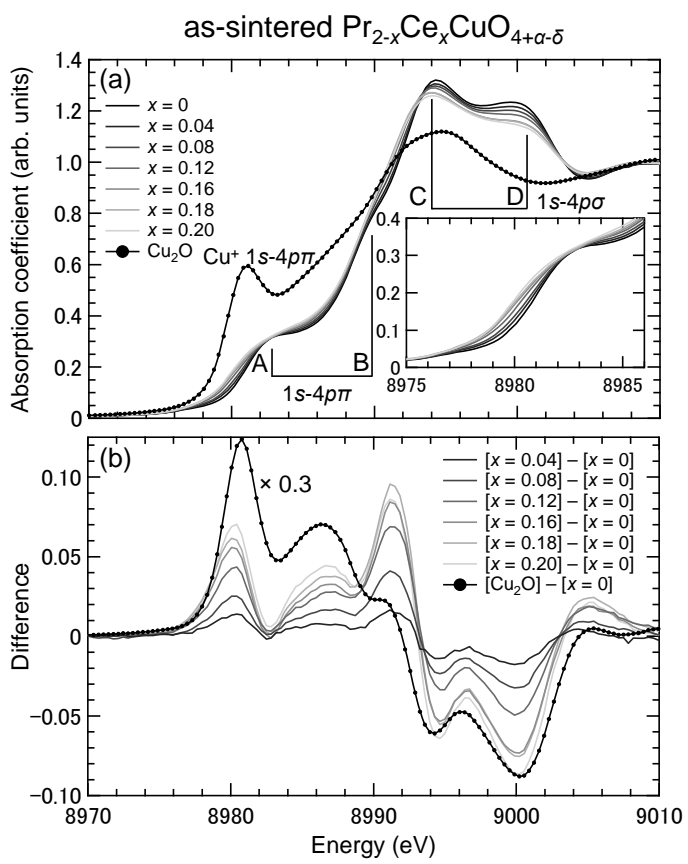
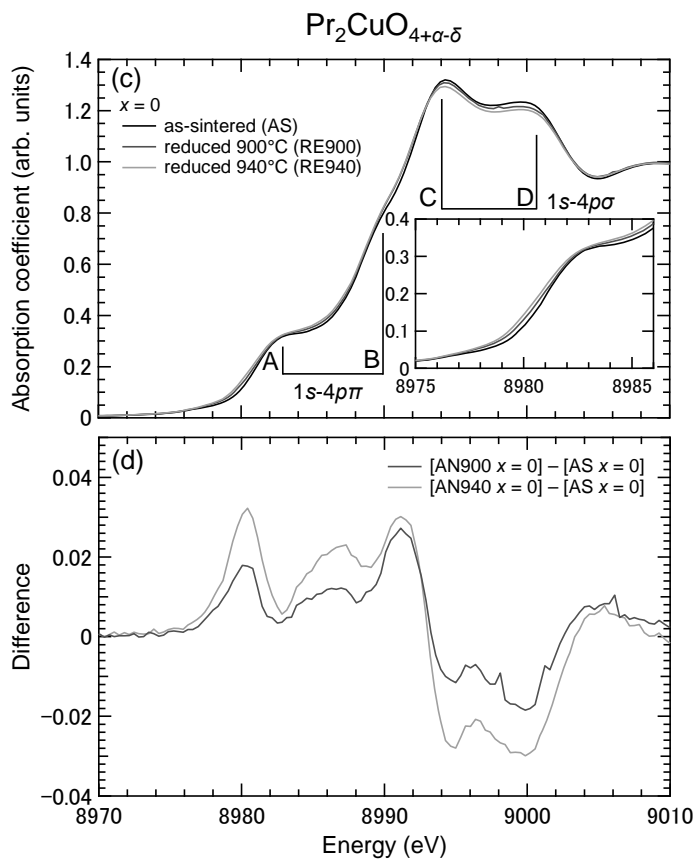

Fig. 2(a) $\mathrm{Cu} K$-absorption near edge spectra and (b) that of difference spectra for as-sintered (AS) $\mathrm{Pr}_{2-x} \mathrm{Ce}_{x} \mathrm{CuO}_{4+\alpha-\delta}$ with $x=$ 0 - 0.20. In Fig. 2(a), the spectrum of $\mathrm{Cu}_{2} \mathrm{O}$ is shown as a reference. The intensity of the difference spectrum for $\mathrm{Cu}_{2} \mathrm{O}$ is shown after being multiplied by 0.3 in (b). (c) $\mathrm{Cu} K$-absorption near edge spectra and (d) that of difference spectra for as-sintered, annealed at $900{ }^{\circ} \mathrm{C}$ (AN900), and annealed at $940{ }^{\circ} \mathrm{C}$ (AN940) $\mathrm{Pr}_{2} \mathrm{CuO}_{4+\alpha-\delta}$.

てきた.

ところが近年，元素置換をしない母物質であっ ても，適切な還元アニールを施した薄膜試料や低 温合成された粉末試料において超伝導の発現が確 認された[2-4]. この報告により提案された新しい 超伝導相図が Fig. 1(d)である. 従来の相図と比心゙ ると Ce 置換量がゼロの領域まで超伝導相が拡張 している。これまでの相図で見られた反強磁性絶 縁体相（Fig. 1(b), 1(c)）は，頂点酸素や $\mathrm{Cu}$ 欠損と いった完全に取り除けない局所的な構造の乱れに より誘起されたものであり，頂点酸素がない完全 な $\mathrm{T}$ ’構造 $R E_{2} \mathrm{CuO}_{4}$ は常磁性金属であると提案さ れている[5]. つまり, Ce 置換していない母物質 はモット絶縁体ではないことを意味している。こ のことは同時に，母物質の基底状態が $\mathrm{CuO}_{2}$ 面周 辺の局所構造により劇的に変化することを示して おり，T’構造銅酸化物における超伝導は，モット 絶縁体にキャリアドープして生じる，という基本 描像の再考を促している。しかし，アニールによ る構造変化に関しては，未だ充分な情報が得られ ておらず，化学分析から見積もられる僅か数\%の 酸素量変化が，如何にして超伝導発現に繋がるか は明らかとなっていない。

一方，我々が行った母物質 $\mathrm{Pr}_{1.4} \mathrm{La}_{0.6} \mathrm{CuO}_{4}$ の非弾 性中性子散乱実験で，アニールによって全磁気モ ーメントが劇的に減少することを見いだしている. ごく僅かな酸素量変化とこの磁性における変化が いかに関係するのか，また変化の原因を突き止め ることは，超伝導発現に対する磁性の役割という 観点からも重要である。そこで我々は，アニール 効果の本質を理解寸るために, 中性子ビームのみ
ならず，複数の量子ビームを活用した研究を展開 している.

本特集記事では，これまでに著者らが行った T’ 構造 $\mathrm{Pr}_{2-x} \mathrm{Ce}_{x} \mathrm{CuO}_{4+\alpha-\delta}$ に対寸る $\mathrm{X}$ 線吸収分光の研究 について解説する[6]. さらに, 国内外の他の研究 グループで得られた最近の研究成果も紹介し, 量 子ビームのマルチプローブ利用によって進められ ている $\mathrm{T}$ 構造銅酸化物超伝導体の研究について 解説する.

\section{2. $\mathrm{Pr}_{2-x} \mathrm{Ce}_{x} \mathrm{CuO}_{4+\alpha-\delta}$ に対する $\mathrm{X}$ 線吸収分光研究}

Ce 置換，および，還元アニールによる電子状態 の変化を明らかにし，両者を比較するために， T, 構造 $\mathrm{Pr}_{2-x} \mathrm{Ce}_{x} \mathrm{CuO}_{4+\alpha-\delta}$ (PCCO) に対する透過法 X 線 吸収端近傍構造 (X-ray absorption near-edge structure；XANES）実験を行った。ここで, as-sintered 試料に含まれる過剩酸素量は $\alpha$, 還元ア ニールにより欠損した酸素量は $\delta$ である。測定に 用いた粉末試料は固相反応法により作成し, $\mathrm{Ar}$ フ ロー下で $900{ }^{\circ} \mathrm{C}$ ，もしくは， $940{ }^{\circ} \mathrm{C} て ゙$ 還元アニー ル処理を行った. また, 酸素欠損量 $\delta$ は, 還元ア ニール前後の試料の重量変化から見積もった.

XANES 実験は， SPring-8 の BL01B1 と BL14B1 において行った. $\mathrm{Cu}$ の吸収分光測定には, $K$ 端と $L$ 端を利用する 2 種類の測定がある。 $K$ 端の吸収 スペクトルは $1 s-4 p$ の双極子遷移の過程を観測す ることから， $2 p-3 d$ の双極子遷移を観測する $L$ 端 に比べて $3 d$ 軌道の電子状態を直接的に観測でき ない，しかし， $K$ 端はエネルギーが高く, バルク の情報を得るため, 比較的簡易に吸収スペクトル が測定できるという利点がある。そのため，系統 

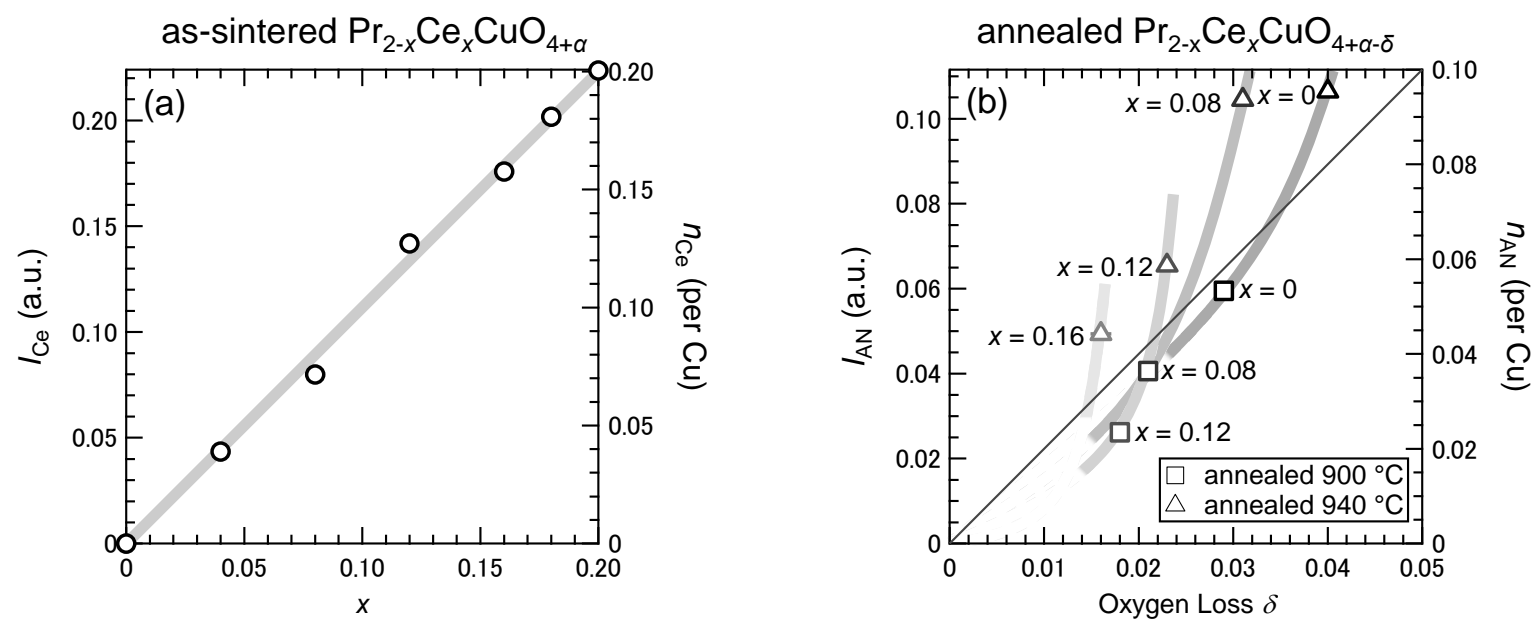

Fig. 3 (a) Ce concentration ( $x$ ) dependence of increased intensity of the $\mathrm{Cu}^{+} 1 s-4 p \pi$ dipole transitions due to Ce substitution $I_{\mathrm{Ce}}$ (left vertical axis) and that of electrons per $\mathrm{Cu}$ due to Ce substitution $n_{\mathrm{Ce}}$ (right vertical axis) for as-sintered $\mathrm{Pr}_{2-x} \mathrm{Ce}_{x} \mathrm{CuO}_{4+\alpha-\delta}$. The solid line is a linear function with $I_{\mathrm{Ce}}=0$ at $x=0$. (b) Increased intensity of the $\mathrm{Cu}^{+} 1 s-4 p \pi$ dipole transitions due to annealing $I_{\mathrm{AN}}$ (left vertical axis) and that of the electrons per Cu due to annealing $n_{\mathrm{AN}}$ (right vertical axis) as a function of oxygen loss $\delta$ for annealed at $900{ }^{\circ} \mathrm{C}$ (AN900), annealed at $940{ }^{\circ} \mathrm{C}$ (AN940) $\mathrm{Pr}_{2-x} \mathrm{Ce}_{x} \mathrm{CuO}_{4+\alpha-\delta}$. The solid line represents a relation of $n_{\mathrm{AN}}=2 \delta$. The solid and dashed curves are guides to the eye for AN900 and AN940 $\mathrm{Pr}_{2-x} \mathrm{Ce}_{x} \mathrm{CuO}_{4+\alpha-\delta}$ with $x=0,0.08,0.12$, and, 0.16, respectively.

的な測定に向いていると期待され， $x$ と $\delta$ の異な る多数の試料を測定対象とする本研究では, Cu K 端を用いた XANES 実験を行った。入射 X線と透 過 X 線の強度をイオンチャンバーにより測定し， 吸収係数を算出した。

PCCO $(x=0-0.2)$ の as-sintered 試料の吸収スペ クトルを Fig. 2(a)に示す. A と B は, $\mathrm{Cu}^{2+} の 1 s-4 p \pi$ の双極子遷移であり, C と D は $\mathrm{Cu}^{2+}$ の $1 s-4 p \sigma$ の双 極子遷移である.また, A と C は, well-screened state で, B と D は poorly-screened state である.さらに, $\mathrm{Cu}^{+}$の参照試料として $\mathrm{Cu}_{2} \mathrm{O}$ のスペクトルを測定し た. Fig. 2 では黒丸で結果を示しており， $8980 \mathrm{eV}$ のピークは $\mathrm{Cu}^{+} の ~ 1 s-4 p \pi$ 双極子遷移に対応する.

Ce 置換量の増加に伴う吸収スペクトルの変化を 見ると， $1 s-4 p \pi$ の遷移強度が増加し， $1 s-4 p \sigma$ の遷 移強度が減少寸る特徵がわかる，そこでこの変化 を浮きだたせるために， $x=0$ を基準として作成し た差分スペクトルを Fig. 2(b)に示す. 差分スペク トルでは，その形状を保ちながら，Ce 置換により 振幅が増大していることが明瞭に見て取れる。こ

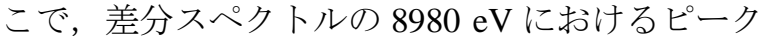
のエネルギー位置は, 参照試料 $\mathrm{Cu}_{2} \mathrm{O}$ で見た $\mathrm{Cu}^{+}$ の $1 s-4 p \pi$ 遷移に対応寸る.従って, このピークは, $R E^{3+}$ が $\mathrm{Ce}^{4+}$ に置換され，電子がドープされたこと により $\mathrm{Cu}^{+}\left(3 d^{10}\right)$ のイトが形成されたことを示 唆している.さらに, $x$ の増加に伴い $8980 \mathrm{eV}$ の ピーク強度, 寸なわち $\mathrm{Cu}^{+}$のサイト数が単調に増 加していることもわかった。

次に, $\mathrm{Pr}_{2} \mathrm{CuO}_{4+\alpha-\delta}$ の還元アニールによる結果を 示寸. Fig. 2(c)の吸収スペクトルの変化に見られ るように, 還元アニールでも $1 s-4 p \pi$ 遷移強度が増 加し， $1 s-4 p \sigma$ 遷移強度が減少した。この変化を明 瞭にするために，上述した方法と同様に， $x=0$ の as-sintered 試料を基準とした差分スペクトルを作 成した。 その結果が Fig. 2(d)である. Ce 置換効果 を示す Fig. 2(b)と比較すると, 還元アニールによ る差分スペクトルの形状は類似していることが分 かる. 従って, 還元アニールは, Ce 置換と同様に 電子ドープの効果があると言える.

これらの結果を基に，8976 eVから $8983 \mathrm{eV} の$ エネルギー領域にある $\mathrm{Cu}^{+} の 1 s-4 p \pi$ 遷移の積分強 度に着目して, 試料中の $\mathrm{Cu}^{+}$の割合, 即ち, 電子 量の定量評価を行った. As-sintered 試料において, Ce 置換により増加した強度 $I_{\mathrm{Ce}}$ を Fig. 3(a)に示す. $I_{\mathrm{Ce}}$ は置換量に比例して増大している. ここで, as-sintered 試料の $\mathrm{Cu}$ サイトあたりの電子キャリア 増加量 $n_{\mathrm{Ce}}$ が Ce 置換量 $x$ に等しいと仮定すること で[7], $n_{\mathrm{Ce}}=I_{\mathrm{Ce}} / 1.116$ の関係を得た.

この関係式を用いて, 次に，アニールより増加 した $\mathrm{Cu}$ あたりの電子量 $n_{\mathrm{AN}}$ の酸素欠損量 $\delta$ 依存性 を評価した. Fig. 3(b)に結果を示している. 図中 の細い害線は $n_{\mathrm{AN}}=2 \delta$ の関係を示しており, 試料 の電気的中性条件により酸素欠損で導入された電 子がすべて $\mathrm{Cu}^{+}$サイのの形成に寄与した場合には, この実線に従う。実験結果は，おおよそ $n_{\mathrm{AN}}=2 \delta$ に沿っているが, 詳細を見ると Ce 置換量によっ て振る舞いが異なっていることがわかった。つま り, $x=0$ では $\delta<0.04$ の比較的広い $\delta$ 領域で $n_{\mathrm{AN}}=$ $2 \delta$ に近い関係にあるのに対し， $x$ が大きくなると 直線関係から外れた上凸の関係に変化する。 この ことは, Ce 置換による電子ドープとは異なる現象 が，アニールで生じていることを示唆する.

ここで, Fig. 3(b)の結果を基に, アニールによる 変化の物理的解䣋を考察する. Cu $K$ 端 XANES で は, $\mathrm{Cu}$ サイトの電子状態, 特に, $\mathrm{Cu}^{+}$のサイト数 に関する情報の取得に有効であり，O サイトに関 


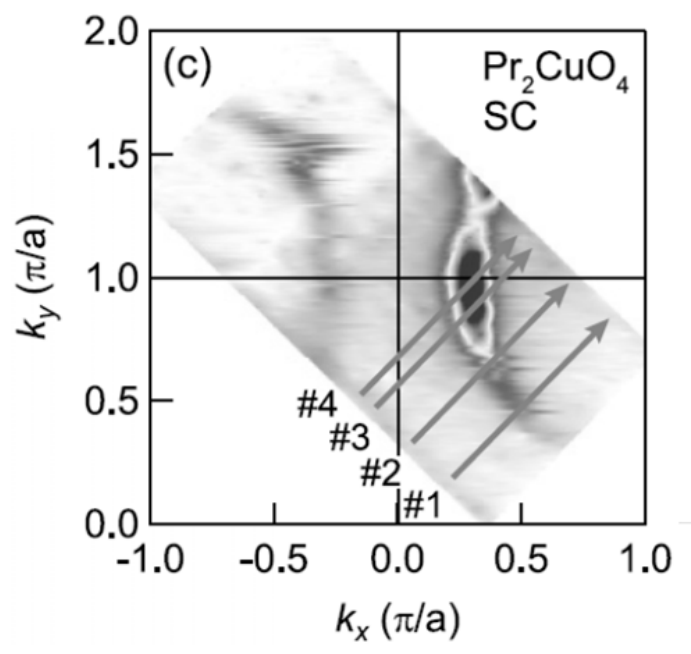

Fig. 4 Fermi surface of superconducting thin film $\mathrm{Pr}_{2} \mathrm{CuO}_{4}$ measured by angle-resolved photoemission spectroscopy [17].

する情報，あるいは，ホールに関する情報はほぼ 得られていない. 実際, $\mathrm{La}_{2-x} \mathrm{Sr}_{x} \mathrm{CuO}_{4}$ におけるホー ルドープによるXANES の変化量は, $\mathrm{Nd}_{2-x} \mathrm{Ce}_{x} \mathrm{CuO}_{4}$ の電子ドープによるそれよりも小さい[12, 13]. こ の実験上の特徵を考慮した場合， $n_{\mathrm{AN}}=2 \delta$ を境界 とした $2 つ の$ 領域に関して, 以下のような考察が できる. i) $n_{\mathrm{AN}}<2 \delta$ の領域では, $n_{\mathrm{AN}}$ は酸素欠損量 から期待される電子量よりも少なく, $\mathrm{CuO}_{2}$ 面に入 つていない電子が存在する. ii) $n_{\mathrm{AN}}>2 \delta$ の領域で は，電気的中性を考慮すると，過剩な電子ととも に，ホールも生成されている.

ここで実際の試料について定量的に考えてみる. 例えば, PCCO $(x=0.12) の 940{ }^{\circ} \mathrm{C}$ annealed 試料で は, $n_{\mathrm{AN}}$ は $0.059 / \mathrm{Cu}$ で $\delta$ は 0.023 である. 酸素欠損 から期待される電子量は $2 \delta=0.046 / \mathrm{Cu}$ であるの で, 過剰にドープされた電子 $\left(n_{\mathrm{AN}}-2 \delta\right)$ は $0.013 / \mathrm{Cu}$ と見積もられる。電気的中性を補償するために, 0.013/Cu のホールキャリアが存在することになる. このように， $n_{\mathrm{AN}}=2 \delta$ を境にしてキャリアの素性 が異なる可能性があり, 多量の酸素を除去するこ とで電子とホールの 2 キャリアが生成されるとい う，アニール効果の新しい側面を本実験では示し た。キャリアの符号を反映するホール抵抗測定か らは，これまでにも，2 キャリアの存在を示唆す る結果が報告されている $[14,15]$. しかし，酸素量 との系統性が示されておらず，統一的な理解には 至っていなかった. Ce 置換量と酸素量によって, 2 キャリアの生成が規定される可能性を我々は示 した．さらに，この考えに基づけば，Ce 置換を施 さない超伝導試料（ノンドープ超伝導体）では， 本実験結果の $x=0.16$ のようにほほんのわずかな 酸素欠損量で 2 キャリアが生成される状況にある と想像できる。この状況が構造に由来するかどう か興味が持たれるところであるが，先ずは低 $\delta$ 領 域で高濃度電子キャリアが生成されるか否かを解 明するため, 現在, 我々のグループではノンドー
プ超伝導体に対する XANES 実験を進行している.

3. $\mathrm{T}^{\prime}$ 構造 $R E_{2-x} \mathrm{Ce}_{x} \mathrm{CuO}_{4}$ に対する最近の実験結果

この節では， $\mathrm{T}^{\prime}$ 構造 $R E_{2-x} \mathrm{Ce}_{x} \mathrm{CuO}_{4}$ に対して行わ れた他の量子ビーム研究を紹介し, 我々の $\mathrm{X}$ 線吸 収分光の結果と比較する。

フェルミ準位近傍の微細電子構造を直接観測で きる光電子分光法は, 電子状態に対する還元アニ 一ル効果を調べる強力な手法である. 東京大学の 藤森グループでは, ノンドープ薄膜試料について 行った光電子分光と軟 $X$ 線吸収分光, 及び, 角度 分解光電子分光 (ARPES) 実験を行い, アニール による電子量の増大を指摘した $[16,17]$. Fig. 4 に, ARPES により観測された, $\mathrm{Pr}_{2} \mathrm{CuO}_{4}$ のノンドープ 超伝導薄膜試料のフェルミ面を示す.フェルミ面

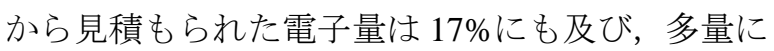
Ce 置換して超伝導が発現するバルク試料の結果 と類似した電子構造であることが示されている. 彼らは，フェルミ面の存在は酸素欠損による電子 ドーピングが要因であると結論付けているが，筆 者の XANES 測定から予測するとホールも生成さ れているはずである。今後, その整合性が確認さ れる必要がある。

磁性に関しては，局所磁性を観測できるミュオ ンスピン回転・緩和（ $\mu S R ）$ 法が強力な研究手法 となり，過㮃酸素などの局所的な構造乱れが磁性 に与える影響がわかると期待される。 上智大学の 足立グループは，様々な還元アニール試料による HSR 時間スペクトルを測定した結果，アニールに より反強磁性転移温度が大きく抑制されるが，ノ ンドープ超伝導試料においても反強磁性ゆらぎ, あるいは, 短距離磁気秩序が存在していると主張 している[18].つまり， T’構造銅酸化物における 超伝導発現には，スピンゆらぎが重要であること を意味している.また, 超伝導相においても反強 磁性ゆらぎが大きいことは，核磁気共鳴実験によ っても示されている[19, 20]. XANES 測定の結果 からは，これら変化はキャリアドープされた事が 要因であると考えられる。

一方，キャリアドープだけでは説明できないア ニール効果が, 我々が最近行った $\mu \mathrm{SR}$ 実験で明ら かになっている。詳細は割愛するが, as-sintered 試料では Ce 置換量に寄らず, $200 \mathrm{~K}$ 程度の温度で 磁気秩序状態が試料に部分的に存在するのに対し, annealed 試料ではその秩序が明瞭には観測されな いという特徵がある。この磁性の違いは，アニー ルによる電子ドープだけでは説明できず, 局所構 造の変化に関係していると考えている. また，最 初に紹介した母物質 $\mathrm{Pr}_{1.4} \mathrm{La}_{0.6} \mathrm{CuO}_{4}$ の磁気励起のア ニールに対する変化も, Ce 置換による磁気励起の 変化とは異なることがわかりつつある[21]. アニ 一ル効果の多面性とその詳細が明らかになりつつ ある現在, 超伝導発現に関与するアニール効果の 本質を注意深く抽出することが最重要課題である. 


\section{4. 今後の展望}

本稿では, $\mathrm{T}$ ’構造 $R E_{2-x} \mathrm{Ce}_{x} \mathrm{CuO}_{4}$ に対する XANES 実験について主に紹介した。アニールによる結晶 構造の変化に関しては，未だ決定的な結果が得ら れていないが，量子ビームの活用により電子状態 や磁性を多元的に調べることで，アニールの微視 的役割と超伝導発現との関係が解明されつつある. また，大型単結晶が得られず実験が限られてきた ノンドープ超伝導についても，そのベールが徐々 にはがされてきている.さらに, ごく最近, 磁気 抵抗の精密測定から, $\mathrm{T}$ 構造 $R E_{2-x} \mathrm{Ce}_{x} \mathrm{CuO}_{4}$ の超伝 導体では 2 キャリアが普遍的に存在し, さらに, 超伝導転移温度がホールによる超流動密度とスケ ールすることが報告された。ホールドープ型 $\mathrm{La}_{2-x} \mathrm{Sr}_{x} \mathrm{CuO}_{4}$ におけるスケーリング則との一致も 指摘されている[22]. 従来, ホールドープ型と電 子ドープ型に分類されてきた銅酸化物超伝導体で あるが，ホールが駆動する統一的な超伝導発現機 構が明らかになれば 30 年来の研究に新たな進展 がもたらされることは間違いない。

\section{謝辞}

本研究は石井賢司，松村大樹，辻卓也，伊奈稔 哲，鈴木謙介各氏との共同研究として行われまし た. $\mathrm{T}$ 構造銅酸化物超伝導体の還元アニール効果 については，足立匡氏に普段より議論を頂きまし た．また，X線吸収分光の解析では，木村優作氏 にご支援いただきました。ここに，感謝の意を表 します. SPring-8 における X 線吸収分光実験は, 2016A1603 と2017B3611により行われました.

\section{参考文献}

[1] H. Takagi et al., Phys. Rev. Lett. 62, 1197 (1989).

[2] M. Naito et al., Supercond. Sci. Technol. 15, 1663 (2002).

[3] O. Matsumoto et al., Physica C 469, 924 (2009).

[4] T. Takamatsu et al., Appl. Phys. Express 5, 073101 (2012).

[5] T. Adachi et al., J. Phys. Soc. Jpn. 82, 063713 (2013).

[6] S. Asano et al., J. Phys. Soc. Jpn. 87, 094710 (2018).

[7]この仮定は，過去に報告されているふたつの 実験結果を根拠としている。1 つ目は，我々の試 料同様に固相反応法で作成した $x=0$ の as-sintered 試料では, 光学伝導度スペクトルに明瞭な電荷移 動ギャップが存在しており，キャリアの存在は確 認できないことである[8,9]. 従って,$x=0$ では $n_{\mathrm{Ce}}=0$ と考えてよい. 2 つ目は, as-sintered 試料に おける反強磁性転移温度や磁気モーメントの Ce 置換量依存性が, spin dilution model でよく理解で きることである $[10,11]$. 従って, as-sintered 試料 では $n_{\mathrm{Ce}}$ が $x$ に等しいと考えられる.

[8] T. Arima et al., Phys. Rev. B 48, 6597 (1993).

[9] Y. Onose et al., Phys. Rev. B 69, 024504 (2004).

[10] B. Keimer et al., Phys. Rev. B 46, 14034 (1992).
[11] P. K. Mang et al., Phys. Rev. Lett. 93, 027002 (2004).

[12] N. Kosugi et al., Phys. Rev. B 41, 131 (1990).

[13] H. Oyanagi et al., Phys. Rev. B 42, 10136 (1990).

[14] Y. Dagan et al., Phys. Rev. Lett. 92, 167001 (2004).

[15] J. Gauthier et al., Phys. Rev. B 75, 024424 (2007).

[16] M. Horio et al., Phys. Rev. Lett 120, 257001 (2018).

[17] M. Horio et al., Phys Rev. B 98, 020505(R) (2018).

[18] T. Adachi et al., J. Phys. Soc. Jpn. 85, 114716 (2016).

[19] M. Yamamoto et al., J. Phys. Soc. Jpn. 85, 024708 (2016).

[20] H. Fukazawa et al., Physica C 541, 30 (2017).

[21] K. Ishii et al., Nature Commun. 5, 3714 (2014).

[22] Y. Li et al., arXiv:1810.04634. 